\title{
利用特殊脉冲电源电沉积制备 $\mathrm{CuInSe}_{2}$ 薄膜
}

\author{
王晓丽，王广君，田宝丽，万绍明，杜祖亮* \\ 河南大学特种功能材料教育部重点实验室, 开封 475004 \\ * 联系人, E-mail: zld@ @enu.edu.cn \\ 2009-07-10 收稿, 2009-09-14 接受 \\ 国家自然科学基金(批准号: 90306010, 10874040)和高等学校科技创新工程重大项目培育资金(编号: 708062)资助项目
}

\begin{abstract}
摘要采用钟形波调制的方波脉冲电源以恒电流模式在导电玻璃基底(ITO)上电沉积制得了 $\mathrm{CuInSe}_{2}$ 薄膜，用扫描电子显微镜(SEM)、X 射线能谱仪(EDS)和 X 射线衍射仪(XRD)对在不同 频率下制备的 $\mathrm{CuInSe} 2$ 薄膜的表面形貌、成分组成和组织结构进行了研究. 结果发现, 在合适 频率下制得的薄膜表面平整, 颗粒均匀致密, 成分接近理想化学计量比, 具有单一的黄铜矿结 构. 在氮气气氛下退火处理后, 薄膜结晶性能有较大提高. 同时, 通过薄膜截面分析发现, 在
\end{abstract} 脉冲恒电流模式下沉积速率较快, 膜层与基底结合紧密, 对工业化生产具有重要意义.

关键词

钟形波

脉冲电沉积

恒电流模式

$\mathrm{CuInSe}_{2}$ 薄膜

太阳能电池
$\mathrm{CuInSe}_{2}(\mathrm{CIS})$ 是一种直接带隙半导体材料, 根据 制备条件及外界环境不同，其禁带宽度可在 $0.95 \sim 1.04 \mathrm{eV}$ 范围内变化. 光吸收系数高达 $10^{5} \mathrm{~cm}^{-1}$ 量级, 通常只需 1 2 $\mu \mathrm{m}$ 即可满足作为太阳能电池吸 收层的要求. 并且其光电转换效率高、寿命长、抗辐 射能力强, 使得 CIS 薄膜太阳能电池成为当今光伏领 域的研究热点 ${ }^{[1 \sim 3]}$.

$\mathrm{CuInSe}_{2}$ 薄膜的制备方法很多, 包括真空蒸镀 法 $^{[4]}$ 、溅射法 ${ }^{[5]}$ 、化学浴沉积法 ${ }^{[6]}$ 、金属有机物化学 气相沉积法 ${ }^{[7]}$ 、分子束外延法 ${ }^{[8,9]}$ 、喷射热解法 ${ }^{[10]}$ 、封 闭空间气相输运 ${ }^{[11]}$ 等. 但是这些方法有的需要昂贵 的真空设备和复杂的制备工艺, 有的是在高温条件 制备, 还有些在制备中使用有毒气体, 因此都有一定 的局限性, 不利于工业化生产. 而电沉积法 ${ }^{[12 ~ 15]}$ 是 一种低温沉积方法, 设备简单, 薄膜的厚度和颗粒大 小易于控制, 并且可以在各种形状复杂的基底上沉 积, 溶液可以回收利用, 可实现大面积连续、多组分 共沉积，因而更适合工业化生产.

电沉积有直流模式和脉冲模式两种. 直流恒电 位模式 ${ }^{[16 ~ 19]}$ 由于只有一个参量(电压或电流)可调节, 薄膜生长过程不易控制, 得到的薄膜往往缺陷较多, 而且不易重复. 而脉冲电源有三个参量可供调节, 即
电压或电流、占空比、频率或周期, 所以使用脉冲电 源进行沉积能明显改善薄膜与基底的结合, 薄膜表 面更平整致密, 元素分布更均匀 ${ }^{[20]}$. 大多数研究者 采用脉冲方波以恒电位模式沉积 ${ }^{[21 ~ 23]} \mathrm{CIS}$ 薄膜, 由于 单脉冲对多种元素共沉积控制能力有限, 所得到的 薄膜的形貌较差且含有杂相. Feng 等人 ${ }^{[24]}$ 采用周期 换向的双向脉冲进行电沉积, 改善了薄膜形貌, 取得 了较好的效果. 另外, 电沉积制备薄膜最主要的控制 因素是电流密度, 以恒电流模式进行沉积, 电流密度 不随电极材料的表面性质而变化, 实验重复性好, 但 是就我们所知, 将该种方法用于电沉积 CIS 薄膜的还 很少. 本文采用钟形波调制的方波脉冲电源以恒电 流模式在水溶液中电沉积制备 CIS 薄膜, 通过采用特 殊的脉冲方式和优化沉积频率, 以较高的沉积速率 得到了颗粒十分均匀致密且成分均匀的薄膜, 为大 面积工业化制备 CIS 薄膜探索了一种新的方法.

\section{1 实验}

(i ) 仪器和试剂. 脉冲电源为实验室发明制作 (专利 CN2010871 49), 退火所用的实验装置为水平 硅碳棒恒温管式炉 (上海意丰仪器制备厂). 原料: 硫 酸铟 (99.99\%, 天津市德兰精细化工); 无水硫酸铜 
(99.99\%，上海亭新化工试剂厂); 亚硒酸(分析纯,天 津市巴斯夫化工有限公司); 柠檬酸钠(分析纯, 天津 市巴斯夫化工有限公司); 硒粉( $99.99 \%$, 成都市科龙 化工有限公司).

(ii) 薄膜的制备. 图 1 为电沉积 CIS 薄膜所用 的脉冲电压示意图. 该脉冲波形为钟形波调制的方 波脉冲, 输出的是可调频率的脉冲直流电. 该脉冲不 仅具有传统脉冲直流电对电极的去极化作用, 由于 经过钟形波的调制, 特别适合多组分共沉积.

电沉积采用两电极电解体系, 使用 Pt 网作对电 极 (阳极), 导电玻璃 (ITO) 为工作电极 (阴极, 大小为 $1.0 \mathrm{~cm} \times 1.5 \mathrm{~cm}$ ), 电解液组成为 $8 \mathrm{mmol} / \mathrm{L} \mathrm{CuSO}_{4}, 100$ $\mathrm{mmol} / \mathrm{L} \mathrm{In}_{2}\left(\mathrm{SO}_{4}\right)_{3}, 16 \mathrm{mmol} / \mathrm{L} \mathrm{H}_{2} \mathrm{SeO}_{3}$ 和 $0.5 \mathrm{~mol} / \mathrm{L}$ 柠 檬酸钠的去离子水溶液, 电解液体积是 $20 \mathrm{~mL}$. 用稀 硫酸将溶液 $\mathrm{pH}$ 调节到 1.5 左右. 沉积频率为 $110 \mathrm{kHz}$, 占空比为 $50 \%$, 沉积电流为 $2 \mathrm{~mA}$, 沉积时间为 $30 \mathrm{~min}$. 沉积结束后, 用去离子水冲洗掉附在前驱体膜上的 柠檬酸钠. 完全晾干后将 CIS 前驱体薄膜放在盛有足 量 $\mathrm{Se}$ 粉的陶瓷舟中, 并将其置人水平管式炉中在 $500^{\circ} \mathrm{C}$ 进行硒化退火, 退火过程中始终通氮气以防止 薄膜被氧化, 退火处理时间为 $30 \mathrm{~min}$.

（iii）表征. 采用日本电子株式会社 JSM$5600 \mathrm{LV}$ 型扫描电子显微镜(SEM) 测定样品的形貌, 并 结合其附件英国 OXFORD 公司的 X 射线能谱仪(EDS) 对样品进行成分分析; 结构表征采用荷兰 X'Pert Pro $X$ 射线衍射仪(XRD)对样品进行测定, $X$ 射线波长为 $1.5406 \AA$, 扫描范围为 $10^{\circ} \sim 80^{\circ}$, 电压为 $40 \mathrm{kV}$, 电流 为 $40 \mathrm{~mA}$. 美国 Varian 公司的 Cary5000 型紫外-可见近红外分光光度计被用于分析样品的吸收特性.

\section{2 结果与讨论}

\section{1 形貌分析}

图 2 为所沉积的 CIS 薄膜的 SEM 形貌图. 从图

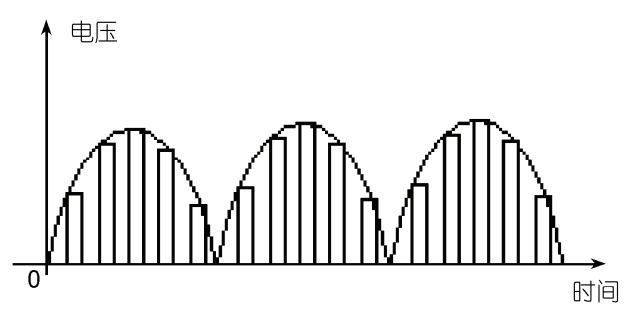

图 1 电沉积铜铟硒薄膜所用的脉冲电压示意图
中我们可以看出, 所制备的薄膜由具有清晰边缘的 球形颗粒密排而成, 十分致密, 膜层平整, 因为平整 的膜有更小的表面积, 而这个面积是太阳能电池中 不同组分间有效的结面积, 减小它可使器件暗电流 变低, 还可减小 CIS 薄膜与窗口层间的表面态密度, 从而提高电池效率 ${ }^{[25 ~ 27]}$.

\section{2 薄膜成分分析}

图 3 为所制备的 CIS 薄膜的 EDS 图谱, 表 1 为 相应的分析结果. 由图 3 我们可以看出, 薄膜样品中 只含有 $\mathrm{Cu}, \mathrm{In}$ 和 $\mathrm{Se}$ 三种元素, 并无其他杂质, 且所用 薄膜均富铜. 根据表 1 的分析结果我们可以看出, 所 制备的薄膜元素分布接近理想化学计量比.

\section{3 退火的影响}

(i ) 形貌分析. 所沉积的 CIS 薄膜在 $500^{\circ} \mathrm{C}$ 进 行退火处理, 退火后薄膜的形貌如图 4(a)所示. 从图 中可以看出, 退火后薄膜形貌并没有太大的变化, 只 是薄膜的颗粒边界更加清晰, 说明退火后其结晶性 能更好. 从退火后薄膜的截面图 4(b)中可以看出, 膜 层与基底结合紧密, 膜层表面平整致密, 薄膜内部由

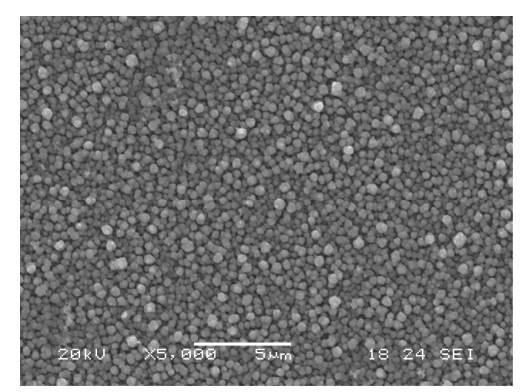

图 2 沉积的 CIS 薄膜样品的表面形貌图

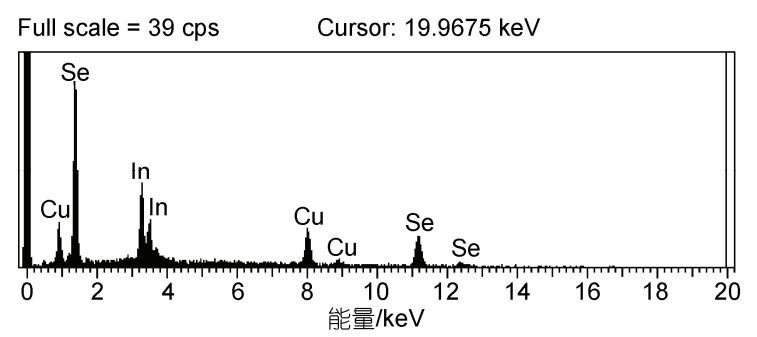

图 3 CIS 薄膜样品的 EDS 图

表 1 EDS 分析结果(原子百分含量)

\begin{tabular}{ccccc}
\hline $\mathrm{Cu} / \%$ & $\mathrm{In} / \%$ & $\mathrm{Se} / \%$ & $\mathrm{Cu} / \mathrm{In}$ & $(\mathrm{Cu}+\mathrm{In}) / \mathrm{Se}$ \\
\hline 22.91 & 22.47 & 54.61 & 1.02 & 0.831 \\
\hline
\end{tabular}



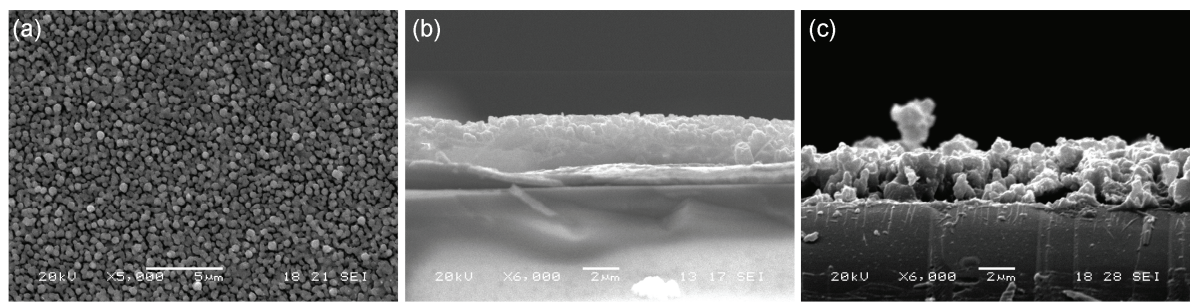

图 4

(a) 经 $500^{\circ} \mathrm{C}$ 退火的 CIS 薄膜样品的表面形貌图; (b) 薄膜的截面图; (c) 在恒电位模式下沉积的薄膜截面图

柱状块体组成, 而在同等条件下, 以直流恒电位模式 沉积 $30 \mathrm{~min}$ 得到的薄膜的截面如图 4(c), 可以看出膜 层较疏松, 且表面凹凸不平整, 与基底结合不牢固, 易脱落. 从两薄膜截面还可以看出, 恒电位模式下薄 膜平均厚度大约为 $4 \mu \mathrm{m}$, 脉冲模式下膜厚大约为 5 $\mu \mathrm{m}$, 表明脉冲恒电流模式沉积速率较快, 这是由于 在脉冲沉积关断时间间隙内, 被消耗的金属离子利 用这段时间扩散补充到阴极附近，当下一个导通时 间到来时，阴极附近的金属离子浓度得以恢复，故可 以维持较高的电流密度, 沉积速率快. 并且脉冲沉积 的峰值电流可以大大高于平均电流, 促使晶种的形 成速度高于晶体长大的速度, 使膜层结晶细化, 排列 紧密, 孔隙减少, 这也是脉冲电沉积优于直流沉积的 主要特点 ${ }^{[28]}$. 而作为太阳能电池的吸收层, 薄膜厚 度只需 $2 \mu \mathrm{m}$ 即可充分吸收人射的太阳光, 所以利用 脉冲沉积可进一步缩短沉积时间, 降低工业化生产的 成本. 另外, EDS 分析表明退火后薄膜的成分与退火 前十分接近, 符合理想化学计量比.

(ii) $\mathrm{X}$ 射线衍射. 图 5 为 CIS 薄膜退火前后的

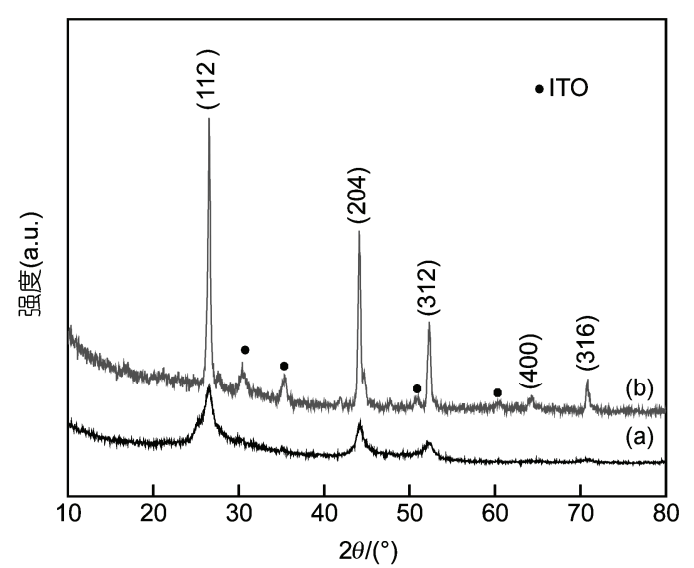

图 5 CIS 薄膜退火前后的 XRD 图

(a) 退火前; (b) 退火后
XRD 图. 可以看出, 沉积的薄膜在未退火之前为黄 铜矿结构, 但衍射峰非常弱且宽, 其结晶度很差. $500^{\circ} \mathrm{C}$ 退火后薄膜的结晶度变好, 最强的三个衍射峰 位置分别在 $26.6^{\circ}, 44.1^{\circ}$ 和 $52.4^{\circ}$, 分别对应黄铜矿结 构的(112), (204)和(312)衍射面. 通过 Scherrer 公式可 以计算出 CIS 膜中颗粒大小:

$$
d=\beta \lambda / B \cos \theta,
$$

其中 $\beta$ 为常数 (0.89), $\lambda$ 为波长 (1.5406 $\AA$ ), $B$ 为衍射峰 半峰宽, $\theta$ 为衍射角, 根据最强衍射峰(也即(112)峰) 估算得到退火前后的晶粒大小分别为 6.2 和 $53.1 \mathrm{~nm}$. 虽然宏观上颗粒变化不太明显, 但是实际上在退火 过程中晶粒变大了. 前面已经提到有关大晶粒薄膜 的优点, 所以经过退火处理后薄膜的结晶性能有较 大提高, 对提高电池效率具有重要作用.

(iii) 吸收性能研究. 图 6 所示为 CIS 薄膜的紫 外-可见-近红外吸收图. 从图中可以看出, 薄膜在 300 1300 nm 波段上具有较强的光吸收(其中 $800 \mathrm{~nm}$ 附近的宽峰是由于仪器换灯引起的), 吸收边对应的 波长为 $1285 \mathrm{~nm}$, 由吸收边波长和禁带宽度值的关系:

$$
\lambda_{\mathrm{g}}=1240 / E_{\mathrm{g}}
$$

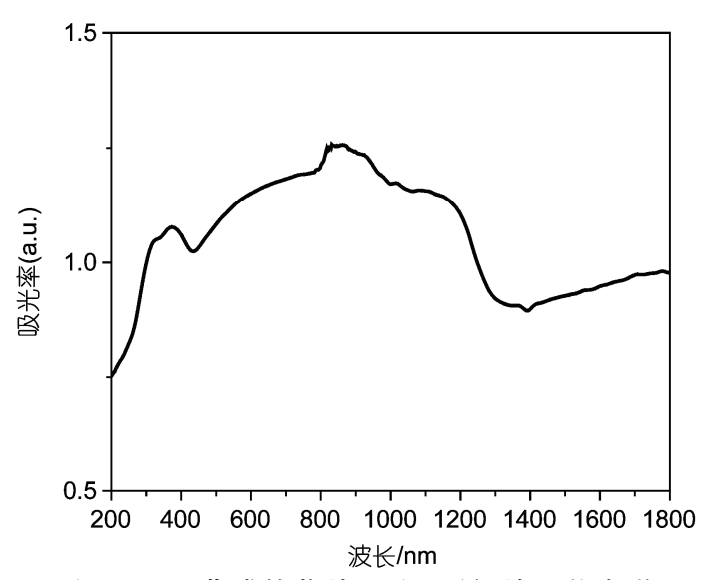

图 6 CIS 薄膜的紫外-可见-近红外吸收光谱 
可知, 该薄膜带隙大约为 $0.965 \mathrm{eV}$, 与文献[12]报道 结果一致.

\section{3 结论}

我们利用钟形波调制的方波脉冲电源, 以恒电 流的模式在导电玻璃基底上电沉积制得了与基底结 合紧密的 $\mathrm{CuInSe}_{2}$ 薄膜. 结果发现, 脉冲频率对薄
膜形貌和成分具有较大的影响. 当脉冲频率为 110 $\mathrm{kHz}$ 时, 制备的薄膜由均匀致密的颗粒组成, 表面平 整, 成分接近理想化学计量比. 退火处理后薄膜的 结晶性明显改善, 具有很强的光吸收, 更适合于太 阳能电池吸收层的应用. 更重要的是, 脉冲恒电流 模式沉积速率快, 可降低工业化生产成本, 具有重 要意义.

\section{参考文献}

1 Jost S, Hergert F, Hock R, et al. Real-time investigations on the formation of $\mathrm{CuInSe}_{2}$ thin film solar cell absorbers from electrodeposited precursors. Sol Energy Mater Sol Cells, 2007, 91: 636-644

2 Kavcar N, Carter M J, Hill R. Characterization of CuInSe 2 thin films produced by thermal annealing of stacked elemental layers. Sol Energy Mater Sol Cells, 1992, 2: 13-23

3 Ingrid R, Miguel A C, Brian E, et al. $19.9 \%$ efficient $\mathrm{ZnO} / \mathrm{CdS} / \mathrm{CuInGaSe}$ solar cell with $81.2 \%$ fill factor. Prog Photovolt Res Appl, 2008, 16: 235-239

4 Contreras M A, Egaas B, Ramanathan K, et al. Progress toward 20\% efficiency in Cu(In,Ga)Se $\mathrm{e}_{2}$ polycrystalline thin-film solar cells. Prog Photovolt Res Appl, 1999, 7: 311-316

5 Muller J, Nowoczin J, Schmitt H, et al. Composition, structure and optical properties of sputtered thin films of CuInSe 2 . Thin Solid Films, 2006, 496: 364-370

6 Pillai V P K, Vijayakumar K P. Characterization of $\mathrm{CuInSe}_{2} / \mathrm{CdS}$ thin-film solar cells prepared using CBD. Sol Energy Mater Sol Cells, 1998, 51: 47-54

7 Yoon S H, Seo K W, Lee S S, et al. Preparation of $\mathrm{CuInSe}_{2}$ thin films through metal organic chemical vapor deposition method by using di- $\mu$-methylselenobis(dimethylindium) and bis(ethylisobutyrylacetato) copper ( II ) precursors. Thin Solid Films, 2006, 515: 1544-1547

8 White F R, Clark A H, Graf M C, et al. Growth of CuInSe $e_{2}$ on CdS using molecular beam epitaxy. J Appl Phys, 1979, 50: 544-545

9 Niki S, Makita Y, Yamada A, et al. Sharp optical emission from CuInSe 2 thin films grown by molecular beam epitaxy. Jpn J Appl Phys, 1994, 33: L500-L502

10 Terasako T, Uno Y, Kariya T, et al. Structural and optical properties of In-rich Cu-In-Se polycrystalline thin films prepared by chemical spray pyrolysis. Sol Energy Mater Sol Cells, 2006, 90: 262-275

11 Kannan M D, Balasundaraprabhu R, Jayakumar S, et al. Preparation and study of structural and optical properties of CSVT deposited $\mathrm{CuInSe}_{2}$ thin films. Sol Energy Mater Sol Cells, 2004, 81: 379-395

12 Oda Y, Matsubayashi M, Minemoto T, et al. Crystallization of In-Se/CuInSe ${ }_{2}$ thin-film stack by sequential electrodeposition and annealing. J Cryst Growth, 2009, 311: 738-741

13 敖建平, 杨亮, 间礼. 硒化前后电沉积贫铜和富铜的 $\mathrm{Cu}\left(\mathrm{In}_{1-x} \mathrm{Ga}_{x}\right) \mathrm{Se}_{2}$ 薄膜成分及结构的比较. 物理学报, 2009, 58: 1870-1878

14 Wellings J S, Samantilleke A P, Heavens S N, et al. Electrodeposition of CuInSe $e_{2}$ from ethylene glycol at 150. Sol Energy Mater Sol Cells, 2009, 93: 1518-1523

15 Whang T J, Hsieh M T, Kao Y C, et al. A study of electrodeposition of CuInSe $e_{2}$ thin films with triethanolamine as the complexing agent. Appl Surf Sci, 2009, 255: 4600—4605

16 Babu S M, Ennaoui A, Lux-Steiner M C. Composition and growth procedure-dependent properties of electrodeposited CuInSe ${ }_{2}$ thin films. J Cryst Growth, 2005, 275: e1241—e1246

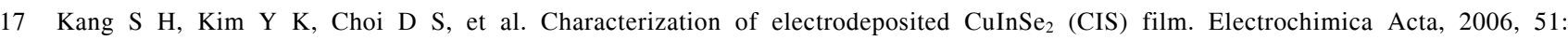
$4433-4438$

18 Ugarte R, Schrebler R, CoÂrdova R, et al. Electrodeposition of CuInSe 2 thin films in a glycine acid medium. Thin Solid Films, 1999, 340: $117-124$

19 Sene C, Calixto M E, Kevin D D, et al. Electrodeposition of $\mathrm{CuInSe}_{2}$ absorber layers from pH buffered and non-buffered sulfate-based solutions. Thin Solid Films, 2008, 516: 2188-2194

20 Chandrasekar M S, Malathy P, et al. Pulse and pulse reverse plating-Conceptual, advantages and applications. Electrochim Acta, 2008, 53: 3313-3322

21 Liu F Y, Lv Y, Zhang Z A , et al. Pulse-plating electrodeposition and annealing treatment of CuInSe $e_{2}$ films. Trans Nonferrous Met Soc 
China, 2008, 18: 884-889

22 Endo S, Nagahori Y, Nomura S. Preparation of thin films by the pulse-plated electrodeposition. Jpn J Appl Phys, 1996, 35: L1101-L1103

23 Nomura S, Nishiyama K, Tanaka K, et al. Preparation of CuInSe $e_{2}$ thin films on Mo coated glass substrates by pulse-plated electrodeposition. Jpn J Appl Phys, 1998, 37: 3232-3237

24 Feng K, Ao J P, Sun G Z, et al. Structure and photovoltaic characteristics of CuInSe $\mathrm{C}_{2}$ thin films prepared by pulse-reverse electrodeposition and selenization process. J Alloy Compd, 2009, 478: L25-L27

25 Gabor A M, Tuttle J R, Albin D S, et al. High-efficiency Culn $\mathrm{Ga}_{1-x} \mathrm{Se}$, solar cells made from $\left(\mathrm{In}_{x}, \mathrm{Ga}_{1-x}\right)_{2} \mathrm{Se}_{3}$ precursor films. Appl Phys Lett, 1994, 65: 198-200

26 Hermanna A M, Mansour M, Badria V, et al. Deposition of smooth $\mathrm{Cu}(\mathrm{In}, \mathrm{Ga}) \mathrm{Se}_{2}$ films from binary multilayers. Thin Solid Films, 2000, 361: 74-78

27 Seto J Y W. The electrical properties of polycrystalline silicon films. J Appl Phys, 1975, 46: 5247-5245

28 于永民, 孙斌. 脉冲电镀应用现状及对策分析. 表面技术, 2006, 35: 82-84

\section{中国科学: 物理学 力学 天文学}

\section{第 40 卷 第 4 期 2010 年 4 月 \\ 目次}

纯音信号双耳响度叠加与双耳声级差及频率的关系

纳米 MOSFET 栅氧化层中吸引型陷阱的参数提取方法………………………………………………….... 395

金属间化合物 $\mathrm{YFe}_{12-x} \mathrm{~V}_{x}$ 中替代元素的致稳机理与系统磁性的理论研究 ………………………………. 400

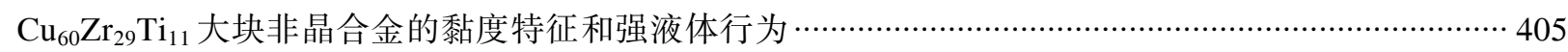

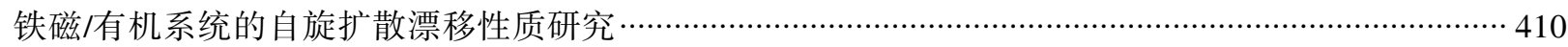

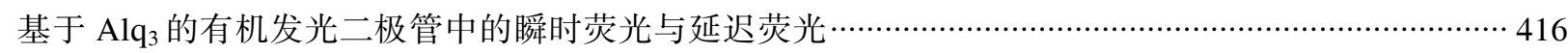

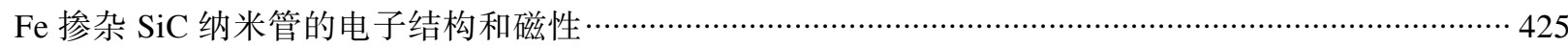

铁磁/绝缘层/有机半导体/铁磁多层膜隧道结的隧穿磁电阻的温度和偏压特性研究……………………4 433

高能碰撞末态粒子相空间分形特性与 HURST 指数的研究 ……………………………………………... 440

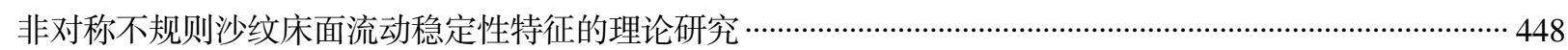

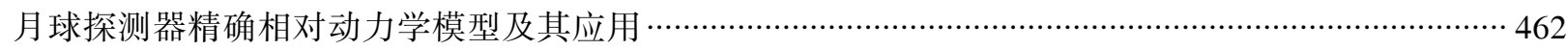

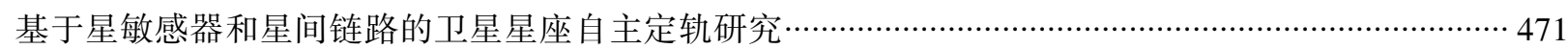

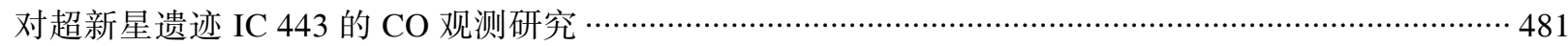

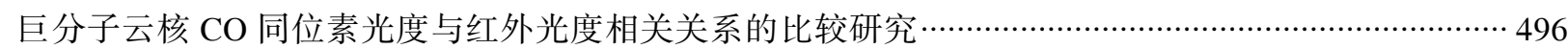

Hamilton-Jacobi 方程和来自 Kerr-TAUB-NUT 黑洞的隧穿辐射 …………………………………………5 507 